\title{
Under- and Normal-Weight Patients Are More Susceptible to Recurrence of Phyllodes Tumor
}

\author{
Yong Yeup Kim $\mathbb{D}^{1},{ }^{1}$ Hayeon Kim ${ }^{D}{ }^{2}$ Woo Young Kim ${ }^{2}{ }^{1}$ Jai Hyun Chung ${ }^{1}{ }^{1}$ \\ Jae Bok Lee $\mathbb{D}^{1},{ }^{1}$ and Sang Uk Woo $\mathbb{D D}^{1}$ \\ ${ }^{1}$ Department of Breast and Endocrine Surgery, Korea University Guro Hospital, Seoul, Republic of Korea \\ ${ }^{2}$ Department of Pathology, Korea University Guro Hospital, Seoul, Republic of Korea \\ Correspondence should be addressed to Sang Uk Woo; suwoo@korea.ac.kr
}

Received 22 September 2021; Accepted 29 November 2021; Published 31 January 2022

Academic Editor: Junwon Min

Copyright ( 2022 Yong Yeup Kim et al. This is an open access article distributed under the Creative Commons Attribution License, which permits unrestricted use, distribution, and reproduction in any medium, provided the original work is properly cited.

Purpose. Phyllodes tumors (PTs) of the breast are rare fibroepithelial neoplasms, and factors associated with the recurrence of PTs are poorly understood. This study sought to identify clinicopathological factors associated with the recurrence of PTs. Method. From January 2009 to December 2019, we identified 100 patients who underwent definitive surgery for PT. Clinicopathological risk factors associated with the recurrence of PT were assessed. Results. The median age of the patients was $44 \mathrm{y}$ (range, 19-62 y), and the median tumor size was $4 \mathrm{~cm}(0.8-30 \mathrm{~cm})$. At a median follow-up of $26.7 \mathrm{mo}(0-103 \mathrm{mo}), 22$ of the 100 patients experienced local recurrence. In the univariate and multivariate analyses, body mass index $\geq 23 \mathrm{~kg} / \mathrm{m}^{2}(P=0.042$ in the univariate analysis; $P=0.039$ in the multivariate analysis), tumor size $\geq 5 \mathrm{~cm}$ ( $P=0.006$ in the univariate analysis; $P=0.036$ in the multivariate analysis), and the presence of stromal overgrowth ( $P=0.032$ in the univariate analysis; $P=0.040$ in the multivariate analysis) were associated with an increased risk of local recurrence. Resection margins and grade were not associated with local recurrence. Conclusion. Normal- or underweight patients and those with larger tumor sizes were more prone to local recurrence. Further larger, multicenter studies with a long-term follow-up are required.

\section{Introduction}

Phyllodes tumors (PTs) are rare breast fibroepithelial neoplasms that account for $0.3 \%-1 \%$ of all breast tumors $[1,2]$. PTs are characterized by biphasic proliferation of both epithelial and stromal components [3]. However, in Asia, its prevalence has increased to $8 \%$ [4]. In general, PTs are classified as benign, borderline, or malignant according to the World Health Organization (WHO) classification and are based on a combination of several histological features, including stromal cellularity, nuclear atypia, mitotic activity, stromal overgrowth, and tumor margin appearance [5]. However, there are no definite criteria or clear cutoffs for the histological parameters. Moreover, diagnosis of PTs and distinction from fibroadenoma after core needle biopsy are challenging and sometimes ambiguous. Unlike fibroadenoma, PTs have the potential for recurrence, with the risk of local recurrence (LR) ranging from $17 \%$ in benign PTs to $27 \%$ in malignant PTs. Distant metastasis occurs in up to $22 \%$ of malignant PTs [5].
The National Comprehensive Cancer Network guidelines recommend wide excision with a margin of $1 \mathrm{~cm}$ or more for each definitive surgery for the treatment of PTs, regardless of the pathological grade [1]. Several retrospective studies have supported this guideline [6]. However, the recent study showed contradictory results. Laura et al. reported that a wider margin width was not associated with a decreased risk of LR, and even a positive margin did not impact LR for benign PTs [7].

Therefore, we looked for unknown clinicopathological risk factors associated with higher LR of PTs.

\section{Materials and Methods}

We reviewed the medical records at Korea University Guro Hospital after institutional review board of Korea University Guro Hospital approval (IRB no. 2021GR0285) based on ethical standards of the Declaration of Helsinki for patients with PTs. Between January 2009 and December 2019, all 
women diagnosed with PT after wide excision or total mastectomy for definitive surgical management were included in the study. The requirement for written informed consent was waived based on the retrospective design of the study. Patient demographic characteristics, clinicopathological data, and survival outcomes were recorded. All available hematoxylin and eosin-stained slides (of selected cases) were reviewed by a pathologist (HK). For the remaining cases, tumor characterization was based on the original pathology report.

Surgical decisions were made at the discretion of the breast surgeon based on the clinically estimated tumor size, breast size, the likelihood of obtaining negative margins, cosmesis, and patient preference. Histological grading was performed by trained breast pathologists based on the 1981 WHO guidelines.

PTs were classified as malignant if the following features were present: marked stromal cellularity and overgrowth, increased nuclear atypia, infiltrative tumor borders, and high mitotic activity of $\geq 10$ mitoses per 10 high-power fields. Any PTs with heterologous sarcomatous elements were also deemed malignant. Borderline PTs were defined as the presence of some, but not all, malignant features. Tumor size was measured as the maximum diameter in the pathological evaluation. For tumors with multiple foci in the same breast, the size was recorded as the maximum diameter of the separate tumor. Multifocality and multicentricity were not distinguishable. The resection margin was defined as positive if tumors were present "on ink" and negative if absent. It included the superficial and deep margins. If reexcision was performed, the margin was based on the last surgical procedure. If the resection margin was recorded as negative, the measured width of the closest negative margin was recorded.

Recurrence-free survival (RFS) was defined as the time interval between initial diagnosis and the first detection of recurrence. LR was defined as pathologically proven tumor recurrence in a previously treated breast.

2.1. Statistics. The base of follow-up was defined as the detection of a recurrent tumor. Surgery due to reexcision was not considered during the follow-up. Optimal cutoff values for body mass index (BMI) were classified based on a BMI of $23 \mathrm{~kg} / \mathrm{m}^{2}$ as the WHO Asian criteria-based BMI. The mass size was classified based on a tumor size of $5 \mathrm{~cm}$. Stromal cellularity, stromal atypia, and mitosis were classified as a three-tiered grading system for PTs based on the 2012 WHO classification [5].

Continuous variables were summarized using median (range), and categorical variables were summarized using number (frequency). Comparisons between benign, borderline, and malignant histologic groups were carried out using the Kruskal-Wallis test for continuous variables and the Mantel-Haenszel test for categorical variables. The RFS rates were calculated using the Kaplan-Meier method. The cumulative incidence of LR was estimated using one minus the Kaplan-Meier estimate of local recurrence-free survival. Cox regression was used to calculate hazard ratios (HRs) to estimate the risk of locoregional recurrence by individual factors. Factors with $P<0.10$ were entered for multivariable competing risks regression based on the Fine and Gray model. Adjusted subdistribution HRs and 95\% confidence intervals (CIs) were calculated. Statistical significance for two-tailed $P$ values was set at $P<0.05$.

All statistical analyses were performed using IBM SPSS version 20 and the open-source statistical software JAMOVI version 1.6.23 (The jamovi Project, Sydney, Australia).

\section{Results}

We identified 100 women with PTs between January 2009 and December 2019. The median patient age was $44 \mathrm{y}$ (IQR, $39-49 y$ ) with a range of $19-62$ y. The median pathological tumor size was $4 \mathrm{~cm}$ (IQR, 2.55-6.5 cm) with a range of $0.8-30 \mathrm{~cm}$. The median patient BMI was $23.7 \mathrm{~kg} / \mathrm{m}^{2}$ (IQR, $21.1-26.3 \mathrm{~kg} / \mathrm{m}^{2}$ ) with a range of $16.1-31.9 \mathrm{~kg} / \mathrm{m}^{2}$. PTs were classified as benign in $65 \%(n=65)$, borderline in $29 \%$ $(n=29)$, and malignant in $6 \%(n=6)$ of the cases (Table 1$)$.

Overall, $92 \%$ of the patients $(n=92)$ underwent wide excision, and $8 \%$ underwent mastectomy $(n=8)$. None of the patients underwent lymph node evaluation. At the initial surgical procedure, $68 \%$ had a negative margin $(n=68)$ and $31 \%$ had a positive margin $(n=31)$. Two patients had lung metastasis, of whom one patient had a malignant phyllodes tumor and the other patient had a borderline phyllodes tumor. The borderline phyllodes tumor patient underwent video-assisted thoracic surgery left lower lobe lobectomy and received an adjuvant chemotherapy at the other hospital. The malignant phyllodes tumor patient died because of multiple lung metastases.

At a median follow-up of $26.7 \mathrm{mo}$ (range, 0-103 mo), 22\% $(n=22)$ of the patients experienced an LR, and none of the patients had a regional recurrence or distant recurrence. LR by grade occurred in 20.0\% $(n=13)$ of 65 benign PTs, $24.1 \%$ $(n=7)$ of 29 borderline PTs, and 33.3\% $(n=2)$ of six malignant PTs. A histological upgrade occurred in $22.7 \%(n=5)$ of LRs (benign to borderline in four cases and benign to malignant in one case). Three patients showed histological downgrades in $13.6 \%(n=3)$ (borderline to benign in three cases). LR occurred at a median of $22.5 \mathrm{mo}$, and 21 of the 22 LRs developed within $5 \mathrm{y}$, with the longest LR occurring over $8 \mathrm{y}$ after surgery (range, 6-98 mo). All patients with recurrence underwent wide excision, except one patient (of the seven patients who experienced more than two recurrences) who underwent mastectomy. The final margin status of these 22 patients with an LR included 14 patients with a final negative margin, five patients with a final positive margin (one benign, three borderline, and one malignant), and three patients with unknown margins (two benign and one borderline).

In the univariate analysis, factors associated with a higher incidence of LR included a $B M I \geq 23 \mathrm{~kg} / \mathrm{m}^{2}$ (HR $=0.405 ; 95 \% \mathrm{CI}, 0.169-0.968 ; P=0.042)$, pathological tumor size $\geq 5 \mathrm{~cm} \quad(\mathrm{HR}=3.506 ; 95 \% \quad \mathrm{CI}, \quad 1.423-8.637$; $P=0.006)$, and aggravated stromal overgrowth $(\mathrm{HR}=2.654$; 95\% CI, 1.086-6.484; $P=0.032$ ). There was no significant association between LR and type of surgery, pathological grade, stromal hypercellularity, cellular atypia, mitosis, tumor border, and resection margin. 
TABLE 1: Clinicopathological characteristics of the study cohort.

\begin{tabular}{|c|c|c|c|c|c|}
\hline Characteristic & All $(n=100)$ & Benign $(n=65)$ & Borderline $(n=29)$ & Malignant $(n=6)$ & $P$ value \\
\hline $\begin{array}{l}\text { Median age: } \mathrm{y} \text { (range) } \\
\text { Median body Mass index: } \mathrm{kg} / \mathrm{m}^{2} \text { (range) } \\
\text { Median pathological tumor size: cm (range) }\end{array}$ & $\begin{array}{c}44(19-62) \\
23.7(16.1-31.9) \\
4.0(0.8-30.0) \\
\end{array}$ & $\begin{array}{c}44(19-62) \\
23.3(16.1-31.9) \\
3.5(0.8-9.5) \\
\end{array}$ & $\begin{array}{c}45(19-59) \\
24.1(17.0-31.4) \\
6.5(1.2-30.0) \\
\end{array}$ & $\begin{array}{c}40.5(29-50) \\
26.8(21.5-31.8) \\
6.5(2.4-25.0) \\
\end{array}$ & $\begin{array}{l}P=0.561 \\
P=0.219 \\
P=0.004\end{array}$ \\
\hline $\begin{array}{l}\text { Recurrence, } n(\%) \\
\text { Not recurred } \\
\text { Recurred }\end{array}$ & $\begin{array}{l}78(78) \\
22(22)\end{array}$ & $\begin{array}{l}52(80) \\
13(20)\end{array}$ & $\begin{array}{c}22(76) \\
7(24)\end{array}$ & $\begin{array}{l}4(67) \\
2(33)\end{array}$ & $P=0.429$ \\
\hline $\begin{array}{l}\text { Surgery, } n(\%) \\
\text { Wide excision } \\
\text { Mastectomy } \\
\end{array}$ & $\begin{array}{c}92(92) \\
8(8)\end{array}$ & $\begin{array}{c}65(100) \\
0(0) \\
\end{array}$ & $\begin{array}{c}23(79) \\
6(21) \\
\end{array}$ & $\begin{array}{l}4(67) \\
2(33) \\
\end{array}$ & $P<0.001$ \\
\hline $\begin{array}{l}\text { Stromal cellularity, } n(\%) \\
\text { Mild } \\
\text { Moderate } \\
\text { Marked } \\
\text { Unknown }\end{array}$ & $\begin{aligned} 30 & (30) \\
61 & (61) \\
7 & (7) \\
2 & (2)\end{aligned}$ & $\begin{aligned} 26 & (40) \\
37 & (57) \\
0 & (0) \\
2 & (3)\end{aligned}$ & $\begin{array}{c}4(14) \\
22(76) \\
3(10) \\
0(0)\end{array}$ & $\begin{array}{l}0(0) \\
2(33) \\
4(67) \\
0(0)\end{array}$ & $P<0.001$ \\
\hline $\begin{array}{l}\text { Cellular atypia, } n \\
\quad \text { Mild } \\
\text { Moderate } \\
\text { Marked } \\
\text { Unknown } \\
\end{array}$ & $\begin{aligned} & 70(70) \\
& 21(21) \\
& 7(7) \\
& 2(2) \\
&\end{aligned}$ & $\begin{aligned} & 61(94) \\
& 2(3) \\
& 0 \\
& 2(3) \\
&\end{aligned}$ & $\begin{aligned} & 9(31) \\
& 19(66) \\
& 1(3) \\
& 0(0) \\
&\end{aligned}$ & $\begin{array}{c}0(0) \\
0(0) \\
6(100) \\
0(0) \\
\end{array}$ & $P<0.001$ \\
\hline $\begin{array}{l}\text { Mitosis, } n \\
\quad 0-4 \\
5-9 \\
\leq 10 \\
\text { Unknown }\end{array}$ & $\begin{aligned} 66 & (66) \\
15 & (15) \\
13 & (13) \\
6 & (6)\end{aligned}$ & $\begin{array}{c}56(86) \\
4(6) \\
0 \\
5(8)\end{array}$ & $\begin{array}{l}10(35) \\
11(38) \\
7(24) \\
1(3)\end{array}$ & $\begin{array}{c}0(0) \\
0(0) \\
6(100) \\
0(0)\end{array}$ & $P<0.001$ \\
\hline $\begin{array}{l}\text { Borders, } n \\
\text { Pushing } \\
\text { Infiltrative } \\
\text { Unknown } \\
\end{array}$ & $\begin{array}{c}14(14) \\
84(84) \\
2(2)\end{array}$ & $\begin{aligned} & 1(2) \\
& 62(95) \\
& 2(3) \\
&\end{aligned}$ & $\begin{aligned} 9 & (31) \\
20 & (69) \\
0 & (0)\end{aligned}$ & $\begin{array}{c}4(67) \\
2(33) \\
0(0) \\
\end{array}$ & $P<0.001$ \\
\hline $\begin{array}{l}\text { Stromal overgrowth, } n \\
\text { No } \\
\text { Yes } \\
\text { Unknown }\end{array}$ & $\begin{array}{c}79(79) \\
19(19) \\
2(2) \\
\end{array}$ & $\begin{aligned} & 61(94) \\
& 2(3) \\
& 2(3) \\
&\end{aligned}$ & $\begin{array}{c}15(52) \\
14(48) \\
0(0) \\
\end{array}$ & $\begin{array}{c}3(50) \\
3(50) \\
0(0) \\
\end{array}$ & $P<0.001$ \\
\hline $\begin{array}{l}\text { Heterologous component, } n \\
\text { No } \\
\text { Yes } \\
\text { Unknown }\end{array}$ & $\begin{aligned} & 95(95) \\
& 3(3) \\
& 2(2) \\
&\end{aligned}$ & $\begin{aligned} & 62(95) \\
& 1(2) \\
& 2(3) \\
&\end{aligned}$ & $\begin{array}{c}29(100) \\
0(0) \\
0(0) \\
\end{array}$ & $\begin{array}{c}4(67) \\
2(33) \\
0(0) \\
\end{array}$ & $P=0.008$ \\
\hline $\begin{array}{l}\text { Final margin, } n \\
\text { Negative } \\
\text { Positive } \\
\text { Unknown }\end{array}$ & $\begin{aligned} 68 & (68) \\
31 & (31) \\
1 & (1)\end{aligned}$ & $\begin{aligned} 47 & (72) \\
17 & (26) \\
1 & (2)\end{aligned}$ & $\begin{array}{c}19(66) \\
10(34) \\
0(0)\end{array}$ & $\begin{array}{c}2(33) \\
4(67) \\
0(0)\end{array}$ & $P=0.065$ \\
\hline
\end{tabular}

In the multivariate analysis, preoperative BMI $(<23 \mathrm{~kg} /$ $\mathrm{m}^{2}$ vs. $\geq 23 \mathrm{~kg} / \mathrm{m}^{2}$ : $\mathrm{HR}=0.386 ; 95 \%$ CI, 0.156-0.954, $P=0.039)$, pathological tumor size $(<5 \mathrm{~cm}$ vs. $\geq 5 \mathrm{~cm}$ : $\mathrm{HR}=2.671 ; 95 \% \mathrm{CI}, 1.066-6.694, P=0.036)$, and stromal overgrowth (absent vs. present: $\mathrm{HR}=2.706$; 95\% CI, 1.046-6.999, $P=0.040$ ) were associated with LR (Table 2).

Only two patients received adjuvant chemotherapy, and one patient received adjuvant radiotherapy; thus, the influence of these therapies on LR could not be analyzed. Almost all patients survived without disease, except for one patient who died of the disease.

\section{Discussion}

This study aimed to predict the patient group that was expected to have a high recurrence rate by analyzing the factors affecting the recurrence of PTs and to improve the outcome through early detection of recurrence by performing close postoperative follow-up. In the results, a tumor size of $\geq 5 \mathrm{~cm}$ and a BMI of $<23 \mathrm{~kg} / \mathrm{m}^{2}$ were confirmed as factors that caused more recurrences after local excision of PTs, Figure 1.

This study enrolled 10 year-data and used appropriate statistical methods. So, the cohort is sufficient, and study results are suitable. Unfortunately, however, the median follow-up is close to the median disease-free survival. Therefore, long-term follow-up after surgery in patients with a tumor size $\geq 5 \mathrm{~cm}$ or underweight or normal weight according to the Asian standard BMI can reduce missed recurrences and increase patient satisfaction after surgery. With early detection, surgery can be performed with a minimal resection area.

PTs are, in many cases, indistinguishable from fibroadenoma because of the inaccuracy of core needle biopsy 
TABLE 2: Factors associated with locoregional recurrence of phyllodes tumor.

\begin{tabular}{|c|c|c|c|c|c|c|c|c|}
\hline Variables & $\begin{array}{l}\text { No local } \\
\text { recurrence }\end{array}$ & $\begin{array}{l}\text { Local } \\
\text { recurrence }\end{array}$ & $\begin{array}{c}\text { HR } \\
\text { (univariate) }\end{array}$ & $\begin{array}{c}95 \% \text { CI } \\
\text { (univariate) }\end{array}$ & $\begin{array}{c}P \\
\text { value }\end{array}$ & $\begin{array}{c}\text { HR } \\
\text { (multivariate) }\end{array}$ & $\begin{array}{c}95 \% \mathrm{CI} \\
\text { (multivariate) }\end{array}$ & $\begin{array}{c}P \\
\text { value }\end{array}$ \\
\hline \multicolumn{9}{|l|}{$B M I$} \\
\hline$<23 \mathrm{~kg} / \mathrm{m}^{2}$ & 29 & 14 & Ref & & & Ref & & \\
\hline$\geq 23 \mathrm{~kg} / \mathrm{m}^{2}$ & 48 & 8 & 0.405 & $0.169-0.968$ & 0.042 & 0.386 & $0.156-0.954$ & 0.039 \\
\hline \multicolumn{9}{|l|}{ OP name } \\
\hline $\begin{array}{l}\text { Wide } \\
\text { excision }\end{array}$ & 71 & 21 & Ref & & & & & \\
\hline Mastectomy & 7 & 1 & 0.753 & $0.101-5.635$ & 0.782 & & & \\
\hline \multicolumn{9}{|l|}{ Size } \\
\hline$<5 \mathrm{~cm}$ & 54 & 7 & Ref & & & Ref & & \\
\hline$\geq 5 \mathrm{~cm}$ & 23 & 15 & 3.506 & $1.423-8.637$ & 0.006 & 2.671 & $1.066-6.694$ & 0.036 \\
\hline \multicolumn{9}{|l|}{ Grade } \\
\hline Benign & 52 & 13 & Ref & & & & & \\
\hline Borderline & 22 & 7 & 0.872 & $0.346-2.197$ & 0.772 & & & \\
\hline Malignant & 4 & 2 & 1.327 & $0.298-5.920$ & 0.711 & & & \\
\hline \multicolumn{9}{|c|}{ Stromal hypercellularity } \\
\hline Mild & 23 & 7 & Ref & & & & & \\
\hline Moderate & 49 & 12 & 0.409 & $0.152-1.099$ & 0.076 & & & \\
\hline Marked & 4 & 3 & 1.089 & $0.277-4.284$ & 0.903 & & & \\
\hline \multicolumn{9}{|l|}{ Cellular atypia } \\
\hline Mild & 56 & 14 & Ref & & & & & \\
\hline Moderate & 15 & 6 & 1.005 & $0.384-2.626$ & 0.992 & & & \\
\hline Marked & 5 & 2 & 1.119 & $0.252-4.973$ & 0.883 & & & \\
\hline \multicolumn{9}{|l|}{ Mitosis } \\
\hline $0-4$ & 56 & 10 & Ref & & & & & \\
\hline $5-9$ & 8 & 7 & 2.821 & $1.060-7.505$ & 0.038 & & & \\
\hline$\leq 10$ & 9 & 4 & 1.446 & $0.452-4.624$ & 0.534 & & & \\
\hline \multicolumn{9}{|l|}{ Tumor border } \\
\hline Pushing & 11 & 3 & Ref & & & & & \\
\hline Infiltrative & 65 & 19 & 1.232 & $0.361-4.211$ & 0.739 & & & \\
\hline \multicolumn{9}{|c|}{ Stromal overgrowth } \\
\hline No & 65 & 14 & Ref & & & & & \\
\hline Yes & 11 & 8 & 2.654 & $1.086-6.484$ & 0.032 & 2.706 & $1.046-6.999$ & 0.040 \\
\hline \multicolumn{9}{|c|}{ Resection margin } \\
\hline Negative & 57 & 11 & Ref & & & & & \\
\hline Positive & 20 & 11 & 1.873 & $0.794-4.419$ & 0.152 & & & \\
\hline
\end{tabular}

HR, hazards ratio; CI, confidence interval; BMI, body mass index; OP, operation.

results and heterogeneity of PTs; vacuum-assisted breast excision (VAE) or surgical excision is chosen based on the clinical features. In general, when a fibroepithelial lesion appears on a core needle biopsy, surgical excision is recommended with the possibility of a PT in mind when the size is large or when it grows rapidly. By applying the results of this study, surgical excision rather than VAE may be recommended for patients with a tumor size of $\geq 5 \mathrm{~cm}$ or a BMI of $<23 \mathrm{~kg} / \mathrm{m}^{2}$, who are expected to have high risk of recurrence before the pathological diagnosis is confirmed. It is thought that it can be helpful to increase disease-free survival or decrease the recurrence rate; however, supporting data through additional research should be confirmed.

In our data, recurrence was common when the size was $\geq 5 \mathrm{~cm}$ or the BMI was $<23 \mathrm{~kg} / \mathrm{m}^{2}$, and the margin status was not related to recurrence. In a recent study, breast volume was found to be related to BMI [8]. That is, the larger the tumor size and the lower the BMI, the smaller the normal breast volume and the more likely the recurrence of PTs.
Many studies have reported that positive margins increase recurrence between surgical margins and recurrence [9-17]. However, based on recent studies, negative margins are not essential for lowering recurrence [18, 19], especially in the setting of a benign PT [20, 21].

Stromal overgrowth influences recurrence; however, the number of mitoses, borders, stromal atypia, and stromal cellularity, which affects the grade based on the WHO classification, did not affect recurrence in this study. Access to cellular atypia and stromal cellularity may be affected by the variability among pathologists. The evaluation of mitoses may also be affected by the number of fields to be analyzed and whether it should be a maximal or average mitotic count [14]. In our pathological report, stromal overgrowth was recorded as binomial; however, cellular atypia and stromal cellularity were expressed as multinomial. Therefore, the relationship between pathological factors and recurrence will be clear only when the clarity of pathological ambiguity is 


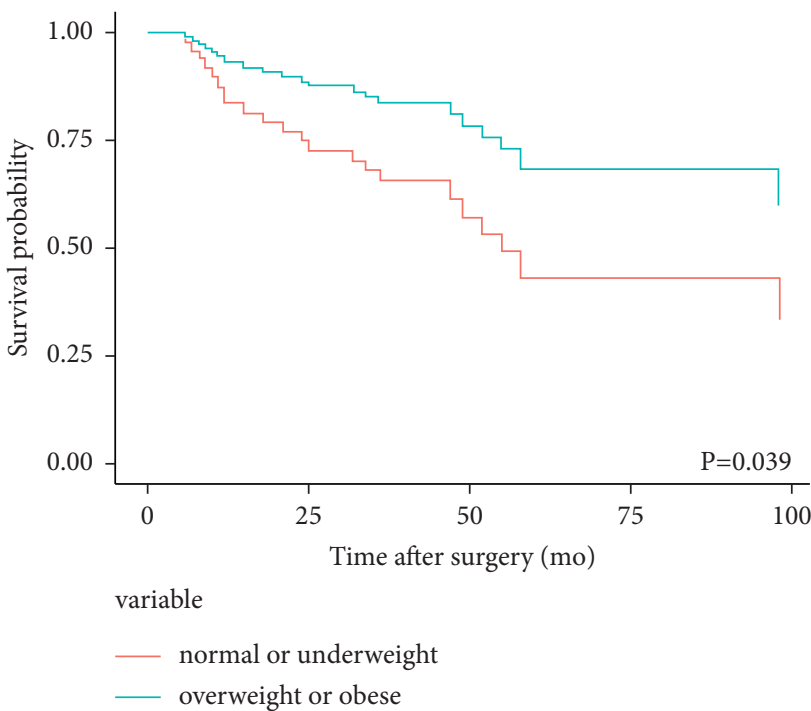

(a)

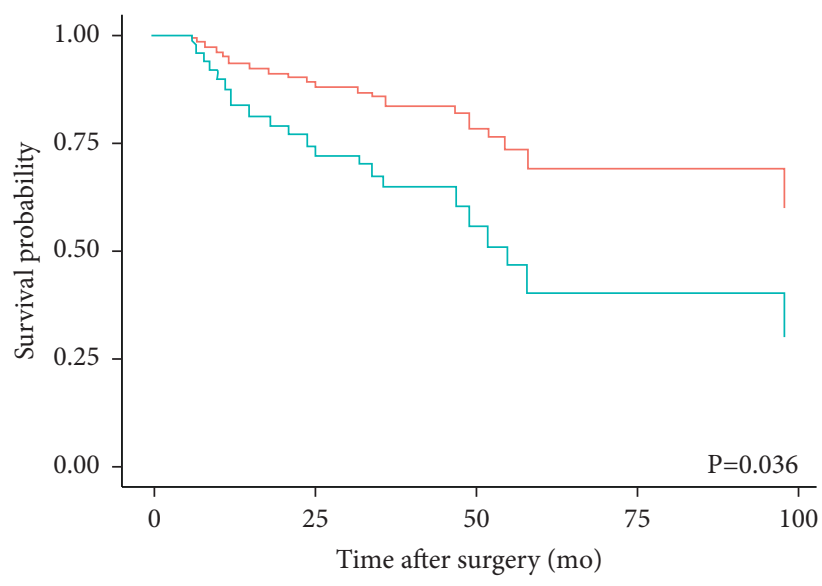

variable

$-<5 \mathrm{~cm}$

$-25 \mathrm{~cm}$

(b)

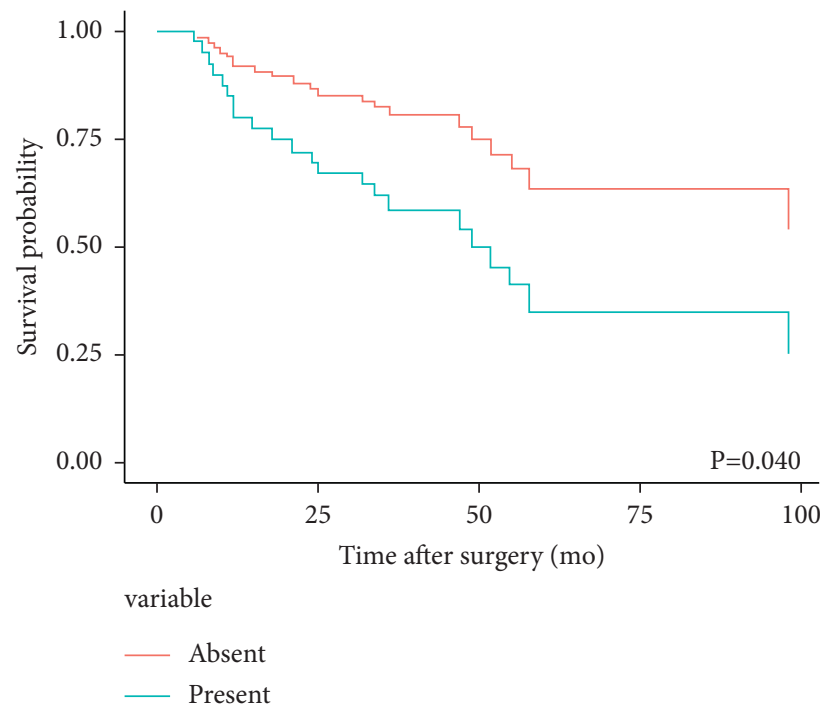

(c)

FiguRe 1: Adjusted local recurrence-free survival curve by a multivariate Cox proportional hazard model of phyllodes tumor. It is subdivided by the body mass index (a), tumor size (b), and stromal overgrowth (c).

established. Until now, only histological features have been used in diagnosing PT; however, gene assays or immunohistochemistry are being studied for diagnosing and grading PT [22]. These studies are expected to clarify the distinction between PT and fibroadenoma and between the grades of PT.

In this study, reexcision was not performed in most patients, even if the margin was positive, and the margin status did not have a statistical significance in recurrence. Nevertheless, the recurrence rate was not significantly different from the recurrence rate reported in a previous study [5], which was generally $20 \%$. These results suggest that the benefit of reexcision is not significant when $\mathrm{R} 1$ resection is performed. However, the superficial and deep margins were not distinguished from the margins, and the total number of patients was insufficient.
The change in the histological grade upon LR is unusual, and our study showed only one case of malignant transformation. Although most of the locally recurrent tumors tended to follow their primary form, the histological transformation was seen not only in upgrading but also in downgrading. Considering the histopathological diversity of $\mathrm{PT}$ and the ambiguous criteria for histological grading, histological downgrading due to insufficient sampling or discrepancies in pathological evaluation cannot be excluded. Additional investigations are required to identify the clinical significance of such histological changes.

This study has certain limitations. First, it was a singlecenter, retrospective study. If a high-quality multicenter or prospective cohort study is performed in the future, factors with a higher-level evidence affecting recurrence can be found. It seems that research in the long-term follow-up 
group after definitive surgery for PTs should be conducted. Second, we did not actually measure the patient's breast size. As a retrospective study, only mammography and ultrasonography remained, so it is impossible to measure the size of the breast. This should be supplemented in future studies.

This study is the first to present the correlation between the recurrence of $\mathrm{PT}$ and $\mathrm{BMI}$, and a more extensive study should be conducted.

\section{Data Availability}

The data used to support the findings of this study are available from the corresponding author upon request.

\section{Conflicts of Interest}

All authors report no conflicts of interest.

\section{Authors' Contributions}

Hayeon Kim contributed equally to this work.

\section{Acknowledgments}

The authors would like to thank Editage (https://www. editage.co.kr) for English language editing.

\section{References}

[1] N. Choi, K. Kim, K. H. Shin et al., "The characteristics of local recurrence after breast-conserving surgery alone for malignant and borderline phyllodes tumors of the breast (KROG 16-08)," Clinical Breast Cancer, vol. 19, no. 5, pp. 345-353, 2019.

[2] Y. Zhang and C. G. Kleer, "Phyllodes tumor of the breast: histopathologic features, differential diagnosis, and molecular/genetic updates," Archives of Pathology \& Laboratory Medicine, vol. 140, no. 7, pp. 665-671, 2016.

[3] J. Tan, C. K. Ong, W. K. Lim et al., "Genomic landscapes of breast fibroepithelial tumors," Nature Genetics, vol. 47, no. 11, pp. 1341-1345, 2015.

[4] P.-H. Tan, T. Jayabaskar, K.-L. Chuah et al., "Phyllodes tumors of the breast," American Journal of Clinical Pathology, vol. 123, no. 4, pp. 529-540, 2005.

[5] S. E. LakhaniS. J. Schnitt et al., "World health organization classification of tumours," Breast Tumours, IARC Press, vol. 2, no. 5, Lyon, France, 2019.

[6] A. V. Barrio, B. D. Clark, J. I. Goldberg et al., "Clinicopathologic features and long-term outcomes of 293 phyllodes tumors of the breast," Annals of Surgical Oncology, vol. 14, no. 10, pp. 2961-2970, 2007.

[7] H. Laura, S. M. T. Rogenberger, S. N. Nimbkar et al., "Contemporary multi-institutional cohort of 550 cases of phyllodes tumors (2007-2017) demonstrates a need for more individualized margin guidelines," Journal of Clinical Oncology, 2020.

[8] C. E. Coltman, J. R. Steele, and D. E. McGhee, "Breast volume is affected by body mass index but not age," Ergonomics, vol. 60, no. 11, pp. 1576-1585, 2017.

[9] W.-H. Chen, S.-P. Cheng, C.-Y. Tzen et al., "Surgical treatment of phyllodes tumors of the breast: retrospective review of 172 cases," Journal of Surgical Oncology, vol. 91, no. 3, pp. 185-194, 2005.
[10] J. Ben Hassouna, T. Damak, A. Gamoudi et al., "Phyllodes tumors of the breast: a case series of 106 patients," The American Journal of Surgery, vol. 192, no. 2, pp. 141-147, 2006.

[11] S.-P. Cheng, Y.-C. Chang, T.-P. Liu, J.-J. Lee, C.-Y. Tzen, and C.-L. Liu, "Phyllodes tumor of the breast: the challenge persists," World Journal of Surgery, vol. 30, no. 8, pp. 1414-1421, 2006.

[12] Y. Belkacémi, G. Bousquet, H. Marsiglia et al., "Phyllodes tumor of the breast," International Journal of Radiation Oncology, Biology, Physics, vol. 70, no. 2, pp. 492-500, 2008.

[13] P. M. Spanheimer, M. P. Murray, E. C. Zabor et al., "Longterm outcomes after surgical treatment of malignant/borderline phyllodes tumors of the breast," Annals of Surgical Oncology, vol. 26, no. 7, pp. 2136-2143, 2019.

[14] P. H. Tan, A. A. Thike, W. J. Tan et al., "Predicting clinical behaviour of breast phyllodes tumours: a nomogram based on histological criteria and surgical margins," Journal of Clinical Pathology, vol. 65, no. 1, pp. 69-76, 2012.

[15] G. Spitaleri, A. Toesca, E. Botteri et al., "Breast phyllodes tumor: a review of literature and a single center retrospective series analysis," Critical Reviews in Oncology, vol. 88, no. 2, pp. 427-436, 2013.

[16] J. H. Jang, M.-Y. Choi, S. K. Lee et al., "Clinicopathologic risk factors for the local recurrence of phyllodes tumors of the breast," Annals of Surgical Oncology, vol. 19, no. 8, pp. 2612-2617, 2012.

[17] M. Co, C. Chen, J. Y. Tsang, G. Tse, and A. Kwong, "Mammary phyllodes tumour: a 15-year multicentre clinical review," Journal of Clinical Pathology, vol. 71, no. 6, pp. 493-497, 2018.

[18] C. K. Yom, W. Han, S.-W. Kim, S. Y. Park, I. A. Park, and D.-Y. Noh, "Reappraisal of conventional risk stratification for local recurrence based on clinical outcomes in 285 resected phyllodes tumors of the breast," Annals of Surgical Oncology, vol. 22, no. 9, pp. 2912-2918, 2015.

[19] S. Kim, J.-Y. Kim, D. H. Kim, W. H. Jung, and J. S. Koo, "Analysis of phyllodes tumor recurrence according to the histologic grade," Breast Cancer Research and Treatment, vol. 141, no. 3, pp. 353-363, 2013.

[20] Y. Lu, Y. Chen, L. Zhu et al., "Local recurrence of benign, borderline, and malignant phyllodes tumors of the breast: a systematic review and meta-analysis," Annals of Surgical Oncology, vol. 26, no. 5, pp. 1263-1275, 2019.

[21] T.-A. Moo, H. Alabdulkareem, A. Tam et al., "Association between recurrence and Re-excision for close and positive margins versus observation in patients with benign phyllodes tumors," Annals of Surgical Oncology, vol. 24, no. 10, pp. 3088-3092, 2017.

[22] Y. Sim, V. K. M. Tan, N. A. B. Sidek et al., "Bilateral breast cancers in an Asian population, and a comparison between synchronous and metachronous tumours," ANZ Journal of Surgery, vol. 88, no. 10, pp. 982-987, 2018. 